\title{
Evaluation of Acute Toxicity and Early Clinical Outcome in Head and Neck Cancers Treated With Conventional Radiotherapy and Simultaneous Integrated Boost Arc Radiotherapy
}

\author{
Amit Bahla, d, Arun S. Oinam $^{\mathrm{a}}$, Satinder Kaur ${ }^{\mathrm{a}}$, Roshan Verma ${ }^{\mathrm{b}}$, Arun Elangovan ${ }^{\mathrm{a}}$, \\ Sudhir Bhandaric, Jaimanti Bakshi ${ }^{\mathrm{b}}$, Naresh Panda ${ }^{\mathrm{b}}$, Sushmita Ghoshal ${ }^{\mathrm{a}}$
}

\begin{abstract}
Background: Chemoradiotherapy plays an important role in management of locally advanced head and neck cancers. This retrospective analysis was done to evaluate and compare acute toxicity profiles and early clinical outcomes in patients treated with conventional and arc techniques.
\end{abstract}

Methods: Fifty-five patients of head and neck cancers were evaluated. Thirty patients received conventional radiotherapy with $6 \mathrm{MV}$ or cobalt 60 and 25 patients were treated with simultaneous integrated boost-volumetric modulated arc radiotherapy (SIB-VMAT) with dose prescription of $66-70 \mathrm{~Gy}$. Concurrent chemotherapy was given as cisplatin injection at $40 \mathrm{mg} / \mathrm{m}^{2}$ weekly or $100 \mathrm{mg} / \mathrm{m}^{2}$ thrice weekly.

Results: The incidence of grade 3-4 mucositis was $56 \%$ versus $83.3 \%$ with SIB-VMAT and conventional treatments $(\mathrm{P}=0.026)$. The incidence of grade $2-3$ xerostomia was $44 \%$ versus $80 \%(\mathrm{P}=0.006)$ in the two groups. Grade 2 dysphagia was seen in $40 \%$ versus $80 \%(\mathrm{P}=$ 0.008 ) favoring the arc treatments. Seventeen patients undergoing arc treatment had complete response compared to 14 in the conventional group $(\mathrm{P}=0.040)$. The median disease-free survival (median \pm standard error) was 16 months ( $11 \pm 1.987$ months $)$ in the conventional and arc groups $(\mathrm{P}=0.073)$.

Conclusion: SIB-VMAT shows a better toxicity profile and a trend towards better disease-free survival when compared to conventional radiotherapy in head and neck cancers.

Keywords: Radiotherapy; Head and neck; Toxicity

Manuscript submitted June 7, 2017, accepted June 15, 2017

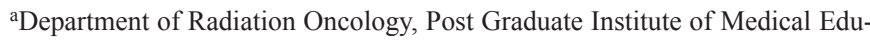
cation \& Research, Chandigarh 160012, India

bDepartment of Otolaryngology, Post Graduate Institute of Medical Education \& Research, Chandigarh 160012, India

${ }^{\mathrm{c}}$ Department of Oral Health Sciences, Post Graduate Institute of Medical Education \& Research, Chandigarh 160012, India

${ }^{\mathrm{d} C}$ Corresponding Author: Amit Bahl, Department of Radiation Oncology, PGIMER, Chandigarh, India. Email: dramitbahl@yahoo.com

doi: https://doi.org/10.14740/wjon1049w

\section{Introduction}

Squamous cell carcinoma of the head and neck region constitutes one of the most common malignancies in the Indian subcontinent. As per Globocan, the estimated annual incidence of head and neck cancers in India is about 144,641 cases with a mortality of 105,247 cases [1]. Radiotherapy alone or in combination with chemotherapy forms an important modality of treatment in locally advanced head and neck cancers. It is estimated that only $36.3 \%$ of all cancer patients in our country have access to radiotherapy facilities and of these a large number receive conventional treatment on cobalt units [2]. Arc treatment is a relatively novel technique that allows for modulation of delivered dose rate, gantry speed and multi-leaf collimator shape while the radiation is delivered [3]. It leads to greater dose homogeneity within the treatment volume with equivalent critical organ sparing when compared to other conformal techniques but with a significant reduction in treatment time [4]. The simultaneous integrated boost (SIB) can be incorporated with arc treatments to further enhance the dosimetric advantage and shorten the overall treatment time [5]. Conventional radiotherapy in head and neck cancers has been delivered using $2 \mathrm{D}$ or $3 \mathrm{D}$ techniques using a combination of parallel opposed or three field portals with a shrinking field approach. The spectrum of acute toxicity during treatment includes radiation dermatitis, mucositis, dysphagia, neutropenia, weight loss, etc. Mucositis can generally be considered to be the dose limiting toxicity in head and neck cancer treatments. Concurrent chemoradiotherapy is associated with grade 3 and 4 toxicity ranging from $32-84 \%$ and $30 \%$ during treatment. Acute grade 3-4 mucositis, dysphagia, and dermatitis up to $19 \%, 16 \%$ and $16 \%$ have been reported in head and neck cancers treated with volumetric modulated arc therapy (VMAT) [6]. In this retrospective analysis, we have reported the incidence of acute toxicity and early clinical outcome observed in our cohort of head and neck cancer patients treated with SIB-VMAT and compared them to those treated with conventional radiotherapy.

\section{Materials and Methods}

The study involved a retrospective review of non-nasopharyn- 
Table 1. Characteristics of the Study Cohort

\begin{tabular}{|c|c|c|c|}
\hline & Conventional radiotherapy, $\mathrm{n}(\%)$ & SIB-VMAT, n (\%) & $\mathbf{P}$ \\
\hline $\mathrm{N}$ & $30(54.55 \%)$ & $25(45.45 \%)$ & \\
\hline Age, median (range), years & $58(35-70)$ & $52(31-65)$ & 0.200 \\
\hline \multicolumn{4}{|l|}{ Sex } \\
\hline Female & $2(6.66 \%)$ & $6(24 \%)$ & 0.069 \\
\hline Male & $28(93.33 \%)$ & $19(76 \%)$ & \\
\hline \multicolumn{4}{|l|}{ Disease subsite } \\
\hline Oral cavity & $8(26.7 \%)$ & $6(24 \%)$ & 0.027 \\
\hline Oropharynx & $15(50 \%)$ & $12(48 \%)$ & \\
\hline Hypopharynx & $5(16.7 \%)$ & $4(16 \%)$ & \\
\hline Unknown primary & $1(3.3 \%)$ & $0(0 \%)$ & \\
\hline Paranasal sinus & $1(3.30 \%)$ & $3(12 \%)$ & \\
\hline \multicolumn{4}{|l|}{ Overall stage } \\
\hline I & $1(3.3 \%)$ & $1(4 \%)$ & 0.333 \\
\hline II & $5(16.7 \%)$ & $0(0 \%)$ & \\
\hline III & $9(30 \%)$ & $9(36 \%)$ & \\
\hline IV & $15(50 \%)$ & $15(60 \%)$ & \\
\hline \multicolumn{4}{|l|}{ Chemotherapy } \\
\hline Weekly & $11(36.7 \%)$ & $9(36 \%)$ & 0.497 \\
\hline Thrice weekly & $7(23.3 \%)$ & $3(12 \%)$ & \\
\hline
\end{tabular}

SIB-VMAT: simultaneous integrated boost-volumetric modulated arc therapy.

geal squamous cell carcinoma of the head and neck treated in our department between March 2015 and September 2016. The analysis included a review of treatment records of 75 patients out of which toxicity data were available for 55 patients. Nasopharyngeal tumors, palliative treatment and re-irradiation patients were excluded from the analysis. The cohort included 35 patients who had received conventional radiotherapy and 25 patients who had undergone SIB-VMAT. The treatment characteristics for the study population are given in Table 1.

\section{Conventional radiotherapy}

For conventional treatments, all patients were immobilized using thermoplastic head and neck casts. Patients undergoing conventional radiotherapy received a dose ranging from 60 to $70 \mathrm{~Gy}$ by shrinking field treatment technique using $6 \mathrm{MV}$ photons or cobalt 60 . Bilateral parallel opposed portals were used to deliver the treatment with spinal cord shielding done at $40 \mathrm{~Gy}$.

\section{SIB-VMAT}

Patients undergoing arc treatment underwent a contrast-enhanced computed tomography treatment planning scan with thermoplastic cast immobilization using a slice thickness of $3 \mathrm{~mm}$. Patients were planned using 3 - 4 arcs with $6 \mathrm{MV}$ photons. Treatment volumes for oropharyngeal cancers were defined as per RTOG 0022 protocol [7]. High risk PTV (PTV66) included gross tumor and nodal disease and received a dose of 66 Gy in 30 fractions. Intermediate risk (PTV60) included the GTV66 and nodal areas with a prescription of 60 Gy in 30 fractions using a margin of $10 \mathrm{~mm}$ from CTV60. For oral cavity and hypopharyngeal lesions, PTV70 received 70 Gy in 33 fractions and PTV59.4 received 59.4 Gy in 33 fractions and elective PTV54 received 54 Gy in 33 fractions [8].

\section{Chemotherapy}

Concurrent chemotherapy was given as infusion of injection cisplatin at $40 \mathrm{mg} / \mathrm{m}^{2}$ weekly or $100 \mathrm{mg} / \mathrm{m}^{2}$ thrice weekly along with radiotherapy.

\section{Acute toxicity assessment}

Acute toxicity was defined as that occurring within 90 days of treatment. All patients were evaluated weekly during the course of treatment using the common terminology criteria for adverse events v3.0 (CTCAE) [9]. Follow-up visits were at 1 month after completion of treatment and twice monthly thereafter.

\section{Statistical analysis}

Statistical analysis was performed using Statistical Package for Social Sciences (SPSS v20). Descriptive statistics were gener- 
Table 2. Treatment Interruptions in Conventional Radiotherapy and SIB-VMAT

\begin{tabular}{llll} 
& Conventional radiotherapy (mean \pm SD) & SIB-VMAT (mean \pm SD) & P \\
\hline OTT (days) & $52.93 \pm 22.81$ & $48.24 \pm 5.0$ & 0.31 \\
Treatment breaks (days) & $4.67 \pm 8.19$ & $1.0 \pm 2.08$ & 0.001 \\
\hline
\end{tabular}

OTT: overall treatment time; SD: standard deviation.

ated for all variables under study. Statistical significance was determined using two-sided tests. Evaluation of clinical and treatment characteristics in conventional and arc cohorts was done using the Chi-square test or Fisher's exact test for categorical variables, and the $t$-test for continuous variables. Survival analysis was done using Kaplan-Meier method. The log-rank test was used to compare the outcomes between arc and conventional treatments. For statistical significance, $\mathrm{P}<0.05$ was considered. Response evaluation criteria for solid tumors (RECISTv1.1) [10] was used to categorize the overall response to treatment.

\section{Results}

Acute toxicity data of 47 males and 8 female patients was evaluated. The median age for the cohort was 55 years. Majority of patients evaluated were diagnosed with stage III and IV disease $(87.27 \%)$. A comparable mean weight loss of $3.93 \pm$ 5.56 and $3.04 \pm 3.52 \mathrm{~kg}$ was seen in conventional and arc treatment groups $(\mathrm{P}=0.49)$. Patients on conventional treatments had more treatment interruptions than in the $\operatorname{arc}$ group $(\mathrm{P}=$ 0.001) (Table 2).

The acute toxicity profile for patients under study is listed in Table 3. Grade 3-4 skin toxicity was seen in 16\% versus $26.7 \%$ in the arc versus conventional groups $(\mathrm{P}=0.340)$. Significantly less patients undergoing SIB-VMAT treatment developed grade 3-4 mucositis as compared to conventional treatment $(56.0 \% \%$ versus $83.3 \%, \mathrm{P}=0.026)$. The incidence of grade 2 xerostomia was $44 \%$ versus $80 \%(\mathrm{P}=0.006)$ in the two groups. Grade 2 dysphagia was seen in $40 \%$ versus $80 \%$ $(\mathrm{P}=0.008)$ in the arc and conventional groups, respectively.

Seventeen patients undergoing arc treatment had complete response compared to 14 in the conventional group $(\mathrm{P}=0.040)$ (Table 4). The median disease-free survival (median \pm stand- ard error (SE)) was $16 \pm 0.00$ and $11 \pm 1.987$ months, respectively (Fig. 1) in the conventional and arc groups $(\mathrm{P}=0.073)$.

\section{Discussion}

Concurrent chemoradiotherapy is the standard of care for locally advanced head and neck cancers with a 5-year survival benefit of $8 \%$ over radiotherapy alone [11]. Both cobalt units and linear accelerators continue to be used for treatment of head and neck cancers in our country. The 95\% depth dose for cobalt and $6 \mathrm{MV}$ treatments occurs at 0.3 and $0.7 \mathrm{~cm}$, respectively [12]. For a $10 \times 10 \mathrm{~cm}$ open field, the surface dose for cobalt and $6 \mathrm{MV}$ beams has been evaluated to be $18 \%$ and $21 \%$ of the $\mathrm{D}_{\max }$ dose, respectively [13].

Intensity modulation techniques have been shown to be equivalent and non-inferior for tumor control in head and neck cancers when compared to conventional treatments. However, toxicity profiles can show differences $[14,15]$. Treatment planning using arc techniques has also been shown to be dosimetrically equivalent to seven field intensity-modulated radiotherapy (IMRT) with similar sparing of organs at risk [16].

Trotti et al reported mucositis in 90\% patients undergoing chemoradiotherapy out of which grade 3-4 mucositis was seen in $43 \%$ patients with treatment interruptions seen in $19 \%$ of cases [17]. Katsoulakis et al reported a rate of grade III mucositis or dysphagia in $38 \%$ and $13 \%$ on conventional radiotherapy and IMRT, respectively [18]. Lambrecht et al reported considerably less $\geq$ grade 3 mucositis in the IMRT patients compared to $3 \mathrm{D}$ conventional radiotherapy $(32 \%$ vs. $44 \%, \mathrm{P}=0.03$ ). A significantly less $\mathrm{xerostomia} \geq$ grade 2 was seen in the IMRT group than in the $3 \mathrm{D}$ conventional radiotherapy group $(23 \%$ vs. $68 \%, \mathrm{P}<0.001)$ [19]. The grade $3-4$ skin reactions and mucositis observed in our study were $16 \% \%$

Table 3. Acute Toxicity Profile of Study Cohort

\begin{tabular}{lllll}
\hline Variable & Grade of toxicity & Conventional radiotherapy & SIB-VMAT & P value \\
\hline Radiation dermatitis & $3-4$ & $26.7 \%$ & $16 \%$ & 0.340 \\
Mucositis & $3-4$ & $83.3 \%$ & $56.0 \%$ & 0.026 \\
Xerostomia & $2-3$ & $80.0 \%$ & $44.0 \%$ & 0.006 \\
Trismus & $3-4$ & $6.7 \%$ & $4 \%$ & 0.440 \\
Dysphagia & $2-3$ & $80.0 \%$ & $40.0 \%$ & 0.008 \\
Constipation & 2 & $6.7 \%$ & $0 \%$ & 0.330 \\
Fatigue & $2-3$ & $6.7 \%$ & $16.0 \%$ & 0.227 \\
Insomnia & 2 & $3 \%$ & $0 \%$ & 0.214 \\
Pain & 2 & $36.7 \%$ & $20.0 \%$ & 0.175 \\
Dysgeusia & 2 & $66.7 \%$ & $76.0 \%$ & 0.448 \\
\hline
\end{tabular}


Table 4. Overall Response to Treatment

\begin{tabular}{llll}
\hline Response & $\begin{array}{l}\text { Conventional } \\
\text { radiotherapy, }\end{array}$ (\%) & $\begin{array}{l}\text { SIB-VMAT, } \\
\text { n (\%) }\end{array}$ & P value \\
\hline CR & $14(46.7 \%)$ & $17(68 \%)$ & \\
Non-CR & $16(53.3 \%)$ & $8(32 \%)$ & 0.040 \\
\hline
\end{tabular}

CR: complete response; non-CR: partial response, stable disease and progressive disease.

and $56 \%$, respectively in the VMAT group $(\mathrm{P}=0.340$ and $\mathrm{P}$ $=0.026)$. Acute xerostomia grade $2-3$ was seen in $44 \%$ of our patients on VMAT treatment $(\mathrm{P}=0.0006)$. Using CTCAE v3, Peng et al reported grade $1-4$ xerostomia of $54.9 \%, 28.1 \%$, $0 \%$ and $0 \%$, and $42.6 \%, 54.2 \%, 3.2 \%$ and $0 \%$ for IMRT and $2 \mathrm{D}$ conventional radiotherapy, respectively at 6 -month followup [20]. The PARSPORT trial also reported a lower incidence of worse than grade 2 xerostomia at 12 months in IMRT versus conventional radiotherapy ( $38 \%$ versus $74 \%, \mathrm{P}=0.002$ ) [15]. An incidence of grade 2 or higher dysphagia of $10.5 \% \mathrm{vs.}$ $3.6 \%$ was seen at 2 years with conventional and IMRT, respectively in oropharyngeal cancers [21]. Grade 2 dysphagia was seen in $40 \%$ of subjects on VMAT treatment $(\mathrm{P}=0.008)$ in our analysis. A higher locoregional control rate at 3 years has been reported in hypopharyngeal cancers treated with IMRT versus $3 \mathrm{D}$ conventional radiotherapy $(75 \%$ vs. $58 \%, \mathrm{P}=0.003)$ but with comparable overall survival rate [22].

Kerr et al reported an overall survival at 3 years of $75.6 \%$ versus $71.5 \%$ for IMRT and 3D conventional radiotherapy in oropharyngeal cancers with a better functional outcome in pa- tients treated with IMRT [23]. A higher incidence of grade 2 fatigue $(16 \%)$ and dysgeusia $(76 \%)$ was seen in patients on VMAT treatment in our study. A higher incidence of fatigue has also been reported in patients undergoing conventional IMRT $[15,24]$. Our results also showed a trend towards a better median disease-free survival of patients on rapid arc treatments versus conventional radiotherapy (16 versus 11 months).

This analysis is limited by the fact that it is a retrospective evaluation with an inhomogeneous population of patients and a short follow- up. Even though conventional treatments can be considered to be technically less superior to image-guided advanced techniques, a mixed clinical practice using both conventional and advanced radiotherapy techniques is still practiced in a lot of radiotherapy centers in developing countries like ours and understanding the toxicity profile helps in better management of these patients.

\section{Conclusion}

SIB-VMAT in head and neck cancer patients is associated with lower incidence of acute toxicities seen as compared to conventional radiotherapy and shows a trend towards better disease-free survival.

\section{References}

1. Globocan 2012: Estimated cancer incidence ,mortality and prevalence worldwide in 2012. Internationa agency

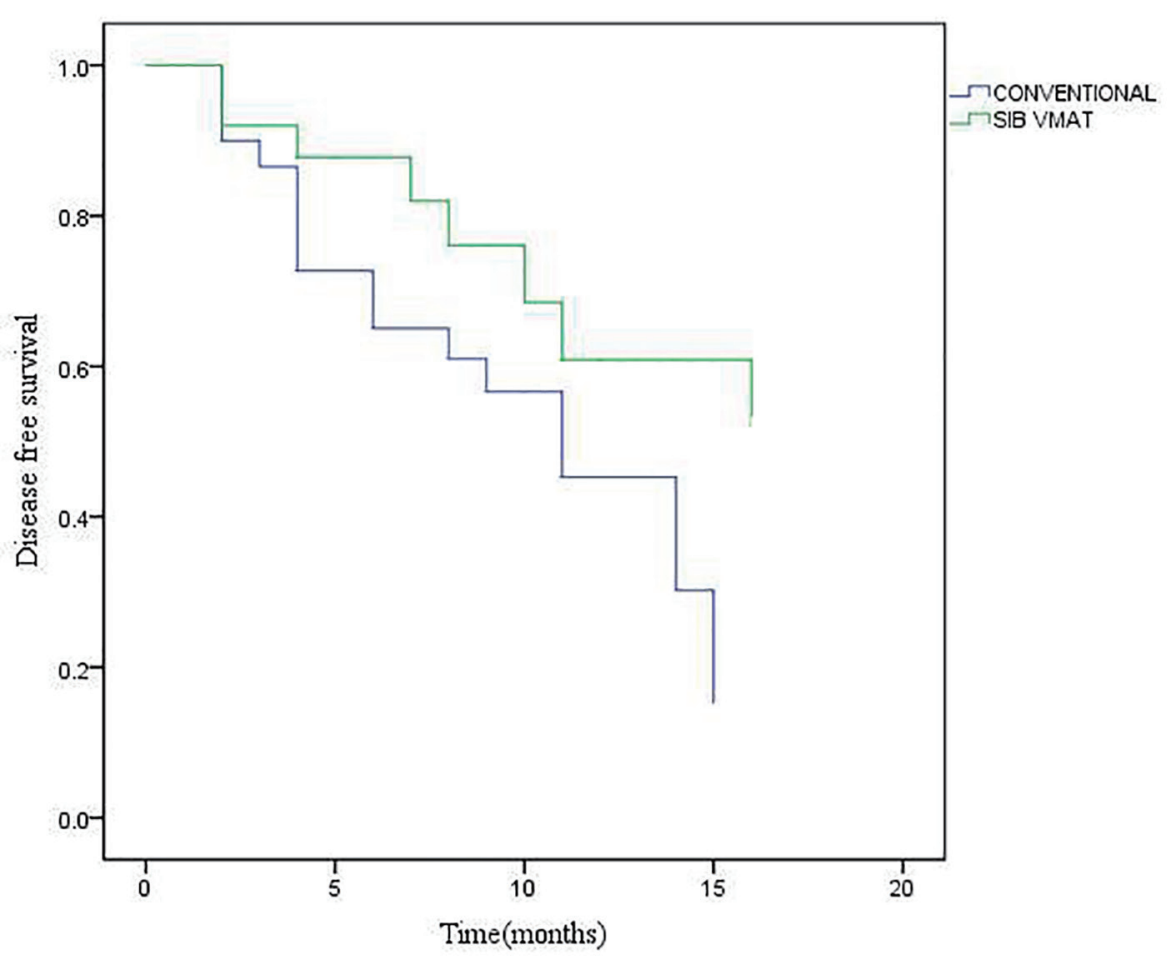

Figure 1. Disease-free survival (DFS) for patients under study. 
for research on cancer.( http://globocan.iarc.fr).

2. Datta NR, Samiei M, Bodis S. Radiation therapy infrastructure and human resources in low- and middle-income countries: present status and projections for 2020. In reply to Sharma et al. Int J Radiat Oncol Biol Phys. 2014;90(4):971-972.

3. Otto K. Volumetric modulated arc therapy: IMRT in a single gantry arc. Med Phys. 2008;35(1):310-317.

4. Vanetti E, Clivio A, Nicolini G, Fogliata A, Ghosh-Laskar S, Agarwal JP, Upreti RR, et al. Volumetric modulated arc radiotherapy for carcinomas of the oro-pharynx, hypo-pharynx and larynx: a treatment planning comparison with fixed field IMRT. Radiother Oncol. 2009;92(1):111117.

5. Wu Q, Mohan R, Morris M, Lauve A, Schmidt-Ullrich R. Simultaneous integrated boost intensity-modulated radiotherapy for locally advanced head-and-neck squamous cell carcinomas. I: dosimetric results. Int J Radiat Oncol Biol Phys. 2003;56(2):573-585.

6. Moncharmont C, Vallard A, Mengue Ndong S, Guy JB, Saget C, Mery B, Langrand-Escure J, et al. Real-life assessment of Volumetric Modulated Arc Therapy (VMAT) toxicity in Head and Neck Squamous Cell Carcinoma (HNSCC) treatment. Acta Otolaryngol. 2016;136(2):181188.

7. Eisbruch A, Harris J, Garden AS, Chao CK, Straube W, Harari PM, Sanguineti G, et al. Multi-institutional trial of accelerated hypofractionated intensity-modulated radiation therapy for early-stage oropharyngeal cancer (RTOG 00-22). Int J Radiat Oncol Biol Phys. 2010;76(5):13331338.

8. Gupta GP, Lee NY. Hypopharangeal carcinoma in Target volume delineation and field set up. Ed: Lee NY, Lu JJ. Springer. 2013:29-34.

9. Trotti A, Colevas AD, Setser A, Rusch V, Jaques D, Budach V, Langer C, et al. CTCAE v3.0: development of a comprehensive grading system for the adverse effects of cancer treatment. Semin Radiat Oncol. 2003;13(3):176181.

10. Eisenhauer EA, Therasse P, Bogaerts J, Schwartz LH, Sargent D, Ford R, Dancey J, et al. New response evaluation criteria in solid tumours: revised RECIST guideline (version 1.1). Eur J Cancer. 2009;45(2):228-247.

11. Pignon JP, le Maitre A, Maillard E, Bourhis J, Group M-NC. Meta-analysis of chemotherapy in head and neck cancer (MACH-NC): an update on 93 randomised trials and 17,346 patients. Radiother Oncol. 2009;92(1):4-14.

12. Tomothy AR, Van Dyk J, Suitcliffe SB. Radiation therapy for hodgkins disease. In: Hodgkins Disease. Selby P, McElwain TJ (eds). 1987:181-149.

13. Kry SF, Smith SA, Weathers R, Stovall M. Skin dose during radiotherapy: a summary and general estimation technique. J Appl Clin Med Phys. 2012;13(3):3734.

14. Gregoire V, De Neve W, Eisbruch A, Lee N, Van den Weyngaert D, Van Gestel D. Intensity-modulated radia- tion therapy for head and neck carcinoma. Oncologist. 2007;12(5):555-564.

15. Nutting CM, Morden JP, Harrington KJ, Urbano TG, Bhide SA, Clark C, Miles EA, et al. Parotid-sparing intensity modulated versus conventional radiotherapy in head and neck cancer (PARSPORT): a phase 3 multicentre randomised controlled trial. Lancet Oncol. 2011;12(2):127136.

16. Verbakel WF, Cuijpers JP, Hoffmans D, Bieker M, Slotman BJ, Senan S. Volumetric intensity-modulated arc therapy vs. conventional IMRT in head-and-neck cancer: a comparative planning and dosimetric study. Int J Radiat Oncol Biol Phys. 2009;74(1):252-259.

17. Trotti A, Bellm LA, Epstein JB, Frame D, Fuchs HJ, Gwede CK, Komaroff E, et al. Mucositis incidence, severity and associated outcomes in patients with head and neck cancer receiving radiotherapy with or without chemotherapy: a systematic literature review. Radiother Oncol. 2003;66(3):253-262.

18. Katsoulakis E, Riaz N, Hu M, Morris L, Sherman E, McBride S, Lee N. Hypopharyngeal squamous cell carcinoma: Three-dimensional or Intensity-modulated radiotherapy? A single institution's experience. Laryngoscope. 2016;126(3):620-626.

19. Lambrecht M, Nevens D, Nuyts S. Intensity-modulated radiotherapy vs. parotid-sparing 3D conformal radiotherapy. Effect on outcome and toxicity in locally advanced head and neck cancer. Strahlenther Onkol. 2013;189(3):223-229.

20. Peng G, Wang T, Yang KY, Zhang S, Zhang T, Li Q, Han $\mathrm{J}$, et al. A prospective, randomized study comparing outcomes and toxicities of intensity-modulated radiotherapy vs. conventional two-dimensional radiotherapy for the treatment of nasopharyngeal carcinoma. Radiother Oncol. 2012;104(3):286-293.

21. McBride SM, Parambi RJ, Jang JW, Goldsmith T, Busse PM, Chan AW. Intensity-modulated versus conventional radiation therapy for oropharyngeal carcinoma: longterm dysphagia and tumor control outcomes. Head Neck. 2014;36(4):492-498.

22. Mok G, Gauthier I, Jiang H, Huang SH, Chan K, Witterick IJ, O'Sullivan B, et al. Outcomes of intensity-modulated radiotherapy versus conventional radiotherapy for hypopharyngeal cancer. Head Neck. 2015;37(5):655-661.

23. Kerr P, Myers CL, Butler J, Alessa M, Lambert P, Cooke AL. Prospective functional outcomes in sequential population based cohorts of stage III/ IV oropharyngeal carcinoma patients treated with $3 \mathrm{D}$ conformal vs. intensity modulated radiotherapy. J Otolaryngol Head Neck Surg. 2015;44:17.

24. Xiao C, Beitler JJ, Higgins KA, Conneely K, Dwivedi $\mathrm{B}$, Felger J, Wommack EC, et al. Fatigue is associated with inflammation in patients with head and neck cancer before and after intensity-modulated radiation therapy. Brain Behav Immun. 2016;52:145-152. 